\title{
Depressive Symptoms and Health-Related Quality of Life in Patients with Cardiovascular Diseases Attending a Tertiary Care Hospital, Puducherry-A Cross-Sectional Study
}

Arokiasamy Senthilkumar ${ }^{1}$ Lakshminarayanan Subitha' ${ }^{1}$ Essakky Saravanan ${ }^{1}$ Dinesh Kumar Giriyappa ${ }^{1}$ Santhosh Satheesh ${ }^{2}$ Vikas Menon ${ }^{3}$

\author{
${ }^{1}$ Department of Preventive and Social Medicine, Jawaharlal Institute \\ of Postgraduate Medical Education and Research (JIPMER), \\ Dhanvantri Nagar, Puducherry, India \\ 2Department of Cardiology, Jawaharlal Institute of Postgraduate \\ Medical Education and Research (JIPMER), Dhanvantri Nagar, \\ Puducherry, India \\ ${ }^{3}$ Department of Psychiatry, Jawaharlal Institute of Postgraduate \\ Medical Education and Research (JIPMER), Dhanvantri Nagar, \\ Puducherry, India
}

J Neurosci Rural Pract 2021;12:376-381.

\author{
Address for correspondence Lakshminarayanan Subitha, MD, \\ Department of Preventive and Social Medicine, Jawaharlal Institute \\ of Postgraduate Medical Education and Research (JIPMER), \\ Dhanvantri Nagar, Puducherry 605006, India \\ (e-mail: subitha.I@gmail.com).
}

\begin{abstract}
Keywords

- cardiovascular disease

- coronary artery disease

- HRQoL

- depression

- patient health questionnaire 9

- EQ-5D-3L

Background Globally, coronary artery disease (CAD) was the leading cause of health losses. The emergence of revascularization has brought a major change in the management of CAD. Depression and cardiovascular diseases (CVD) are the two highly prevalent noncommunicable diseases (NCD), which lead to poor quality of life and high socio-economic loss for the patient. The rate of depressive episodes was higher in CAD population in comparison to population with other heart problems.

Objectives The primary objective of the current study is to determine the proportion of those with depressive symptoms through Patient Health Questionnaire-9 (PHQ-9) among CAD patients in a tertiary care public hospital.

Methods It was a cross-sectional analytical design, which assess the percentage of patients with depressive symptoms among CAD patients, using a pretested, semistructured questionnaire. The PHQ-9 and EuroQoL five-dimensional three-level (EQ-5D-3L) questionnaire, a quality-of-life instrument (five items), were used, which was validated in the Tamil version.

Statistical Analysis Categorical variables was expressed as proportion. We used Chi-square as a statistical test to calculate the $p$ value and risk estimation with $95 \% \mathrm{Cl}$. Results Out of 541 patients, 159 (30\%) patients had mild-to-moderate depressive symptoms, of which 144 (89\%) participants were greater than 50 years. In EQ-5D-3L, around one-third of the participants reported pain or discomfort and anxiety or depression.
\end{abstract}

DOI https://doi.org/

10.1055/s-0041-1724227

ISSN 0976-3147. (c)2021. Association for Helping Neurosurgical Sick People.

This is an open access article published by Thieme under the terms of the Creative Commons Attribution-NonDerivative-NonCommercial-License, permitting copying and reproduction so long as the original work is given appropriate credit. Contents may not be used for commercial purposes, or adapted, remixed, transformed or built upon. (https://creativecommons.org/licenses/by-nc-nd/4.0/).

Thieme Medical and Scientific Publishers Pvt. Ltd. A-12, 2nd Floor, Sector 2, Noida-201301 UP, India 
Conclusion The study concludes that the assessment of health-related quality of life (HRQoL) is becoming increasingly important in the management of CAD patients. Studies have shown that depression predicts subsequent quality of life, while others have shown that HRQoL is a risk factor for ongoing depression. Treatment of depression may improve subsequent physical HRQoL; hence, it is vital to address both during their follow-up to improve outcomes among patients with CAD.

\section{Introduction}

The relation between depression and coronary artery disease (CAD) has been the subject of research since the past two decades. More studies have shown that there was a strong association between depression and prognosis of coronary heart disease (CHD). ${ }^{1}$ Psychological constructs are risk factors for incident CAD and also act as a major risk factors for cardiac morbidity and mortality in the context of established CHD. It also suggests that depression is linked to adverse cardiac outcomes. ${ }^{2}$ Depression and cardiovascular disease (CVD) are two highly prevalent noncommunicable diseases (NCD), which lead to poor quality of life and high socioeconomic loss for the patient. ${ }^{3}$

Globally, CAD was the leading cause of major health losses. The emergence of revascularization has brought a major change in its management. More specifically, percutaneous coronary intervention has become the major modality of treatment, which plays a major role in decreasing the disease burden, thereby decreasing anxiety and depression and increasing quality of life among CAD patients.

The rate of depressive episodes was higher in CAD population as compared with population with other heart problems. Moreover, depression is associated with 2-fold increase in the risk of major adverse cardiac events and mortality. Depression and quality of life were strongly associated in deciding patient's health and recovery. Anxiety and depression also have a major impact on treatment compliance. CAD patients are more liable for mood affect and finally land up with depression This implies that these patients certainly need detection of anxiety and depression for a correct referral and support for the treatment. ${ }^{4}$

The American Heart Association (AHA) recommended that depression following CAD should be considered as one of the risk factors for bad cardiac outcome, as the evidence indicates that it has an association with cardiac mortality and other nonfatal cardiac events. ${ }^{5}$

Health-related quality of life (HRQoL) has a multispectral relation to physical and psychological health, work, leisure time, social functioning, and belongingness in CAD patients. Anxiety and depression are the two factors which have major influence on quality of life, even cause death among CAD patients. Hence, it is important to study HRQoL and psychosocial factors related to their disease status and coping strategies. ${ }^{6}$ Despite the significance of identifying depression in this population, there is paucity of literature in the
Indian context. This study will help to assess its burden and facilitate treatment in CAD patients and this will, in turn, reduce the risk of future cardiac events. Assessing the association between mild-to-moderate depressive symptoms with sociodemographic and behavioral characteristics among cardiac patients can help to plan better treatment strategies. These will also help in planning a suitable cardiac rehabilitation program within the available resources and suitable for our context.

\section{Methodology}

This is a hospital-based cross-sectional study design. The study was conducted in the cardiology outpatient department (OPD) of the superspecialty block from September to November 2018. It has an average of 400 to 450 patients visit as outpatients every day. All patients attending cardiology OPD at JIPMER diagnosed with CHD were considered. The adult patients attending cardiology OPD ( $\geq 18$ years), diagnosed with CHD (post-acute coronary syndrome), patients receiving treatment from cardiology OPD for minimum 3 months, and patients with other major comorbidities like chronic kidney disease, cerebrovascular accident and other peripheral vascular diseases were also included in the study. The patients who were diagnosed to have depression before onset of CHD were excluded from the study. Sample size was calculated using OpenEpi version 3.01. Assuming the prevalence of depressive symptoms in CAD patients to be $34 \%$, $\alpha$ error 5\% (95\% confidence level) and 4\% absolute precision, the sample required is 539 . The sample size was covered between Monday and Thursday from 8 am to $2 \mathrm{pm}$ at the cardiology OPD.

The study participants were selected from cardiology OPD using systematic random sampling technique, based on usual flow rate of patients from the previous day. On an average, around 400 patients visited the clinic each day. Assuming data collection period of 16 days, we were required to cover 34 patients/day. The sampling interval was calculated based on this assumption, that is, 400/34, which gives the sampling interval of around 12 . So, every 12th patient was selected. However, there are fluctuations in patient flow rate; hence, the sampling interval was adjusted accordingly. A pretested, semistructured questionnaire was used for data collection through Epi collect software. It includes the following domains: sociodemographic variables and clinical characteristics; behavioral 
risk factors and adherence to secondary prevention methods were collected. For assessing symptoms of depression, Patient Health Questionnaire-9 (PHQ-9), validated in Tamil version, was used. A cutoff score greater than or equal to 5 is most commonly used to identify mild depression, and those patients who scored above this threshold were considered failed screen and were referred to Department of Psychiatry for further evaluation and management. Various studies have used PHQ-9 to study patients with arthritis, HIV-AIDS, and person with disabilities for depressive symptoms screening. ${ }^{7}$ EuroQOL five-dimensional threelevel (EQ-5D-3L) questionnaire is a self-administered quality-of-life instrument consisting of five dimensions (mobility, self-care, usual activities, pain or discomfort, and anxiety or depression), three levels (mild, moderate, and severe), and a visual analog scale (VAS) scoring from 0 to 100 . Each of the five dimensions is divided into five perceived levels of problems (no, slight, moderate, severe and extreme or unable). It is also used to assess the health utilities in health technology assessment studies. Both instruments were validated in the Indian context and translated into many languages. ${ }^{8}$ After approval from JIPMER Scientific and Ethics committee, the study was carried from September 1 to November 5, 2018 at cardiology OPD JIPMER. Written informed consent was obtained from the subjects. The details were collected through a pretested, semistructured questionnaire.

Data entry was done in EpiCollect 5 and transferred as CSV file to Excel 2016; thereafter, data was exported to IBM Statistical Package of Social Science (SPSS) V.20 for management and analysis. Continuous variables were described as mean and standard deviation (SD) or median and interquartile range (IQR), based on the distribution of the data. Categorical variables were described as proportion. Prevalence of depression was expressed as proportion with 95\% confidence interval (CI). The association between independent variables and presence of depressive symptoms was tested for statistical significance using Chi-square/Fischer's exact test. $p$ value $<0.05$ was considered to be statistically significant. Multivariate analysis was done using binomial logistic regression for independent variables with significant $p$ value $(<0.05)$ to get adjusted odds ratio (OR).

\section{Result}

A total of 541 individuals attended the cardiology clinic during the reference period. Median age for study participants was 45 years, with minimum of 18 years to maximum of 85 years. One-third was between 41 to 50 years of age. Three-fourths were males, and more than half were between class 6 th to 10 th standard. Around two-thirds were unskilled workers and $5 \%$ were housewives. Two-thirds were from Tamil Nadu and the rest were from Puducherry. Regarding socioeconomic classification, mainly around half were from middle class. Majority (93\%) of participants were married (-Table 1).

EQ-5D-3L instrument was used to assess the HRQoL among the study participants, and it included five domains.
Around $15 \%$ participants had problems in mobility. The second domain describes self-care-one-third of participants (29\%) had problems in their self-care activities. More than one-third of participants reported that problem persists in their usual activities. One-third reported pain or discomfort and anxiety or depression (-Table 2 ).

The VAS score describes the HRQoL by imaginable score from 0 to 100, which informs us about their current health marked by the patient. The mean VAS score was 56. Around $80 \%$ of the participants rated their health as moderate, while $7 \%$ said it was the worst imaginable health status (- Table 3 ).

The proportion of depressive symptoms among the study participants was assessed using PHQ-9, which comprises of

Table 1 Sociodemographic characteristics of patients with CAD $(N=541)$

\begin{tabular}{|c|c|c|c|}
\hline Variables & Classes & Frequency & $(\%)$ \\
\hline \multirow[t]{5}{*}{ Age (in years) } & $18-30$ & 60 & 11.1 \\
\hline & $31-40$ & 133 & 24.6 \\
\hline & $41-50$ & 204 & 37.8 \\
\hline & $51-60$ & 110 & 20.4 \\
\hline & $\geq 60$ & 33 & 6.1 \\
\hline \multirow[t]{3}{*}{ Gender } & Male & 396 & 73.2 \\
\hline & Female & 144 & 26.6 \\
\hline & Transgender & 1 & 0.2 \\
\hline \multirow{5}{*}{$\begin{array}{l}\text { Educational } \\
\text { status }\end{array}$} & Illiterate & 46 & 8.5 \\
\hline & Class 1-5 & 139 & 25.7 \\
\hline & Class 6-10 & 316 & 58.4 \\
\hline & Higher secondary & 23 & 4.3 \\
\hline & Graduation & 17 & 3.1 \\
\hline \multirow[t]{3}{*}{ Occupation } & Manual/heavy & 338 & 62.5 \\
\hline & Sedentary & 125 & 23.1 \\
\hline & Unemployed & 78 & 14.4 \\
\hline \multirow[t]{5}{*}{ Residence } & Tamil Nadu & 361 & 66.7 \\
\hline & Pondicherry & 153 & 28.3 \\
\hline & Kerala & 12 & 2.2 \\
\hline & Andhra Pradesh & 6 & 1.1 \\
\hline & Others & 9 & 1.7 \\
\hline \multirow[t]{5}{*}{$\begin{array}{l}\text { Socioeconomic } \\
\text { status }^{\text {a }}\end{array}$} & $\begin{array}{l}<938 \\
\text { (lower class) }\end{array}$ & 26 & 4.8 \\
\hline & $\begin{array}{l}938-1875 \\
\text { (lower middle } \\
\text { class) }\end{array}$ & 5 & 0.9 \\
\hline & $\begin{array}{l}\text { 1876-3126 } \\
\text { (middle class) }\end{array}$ & 260 & 48.1 \\
\hline & $\begin{array}{l}3127-6253 \\
\text { (lower middle } \\
\text { class) }\end{array}$ & 158 & 29.2 \\
\hline & $\begin{array}{l}\geq 6254 \\
\text { (upper class) }\end{array}$ & 40 & 7.4 \\
\hline \multirow[t]{2}{*}{ Marital status } & Married & 501 & 92.6 \\
\hline & Unmarried & 40 & 7.4 \\
\hline
\end{tabular}

Abbreviation: CAD, coronary artery disease.

aModified BG Prasad scale for socioeconomic status (May 2017) 
nine questions related to their daily functioning and coping for the past 2 weeks rated on a scale of 0 to 3 (0-not at all, 1-sometimes, 2-nearly half a day, and 3-nearly all the day). This scale assesses their level of depression like none, mild, moderate, and severe. One-third study participants (29.4\%) had mild depression (score of 5 to 9), while three of them had moderate depression. None of them had severe depression. Prevalence of any depression was 30\% (95\% CI) and this includes mild and moderate forms of depression (-Table 4).

Out of 541 patients, 30\% patients had mild-to-moderate depression, of which 144 (89\%) participants were greater than 50 years, $20 \%$ were females, and one-third had educational status until primary level. Individuals belonging to age category more than 50 years had 5.3 times higher odds of

Table 2 HRQoL among patients with CAD attending cardiology clinic in a tertiary hospital, assessed by EQ-5D ( $N=541)$

\begin{tabular}{|l|l|l|}
\hline $\begin{array}{l}\text { Domains of } \\
\text { EQ-5D tool }\end{array}$ & Frequency \\
\hline Mobility & $\%$ \\
\hline No problems & 459 & 84.8 \\
\hline Have problems & 82 & 15.2 \\
\hline Self-care & 71.5 \\
\hline No problems & 387 & 28.5 \\
\hline Have problems & 154 & 65.1 \\
\hline Usual activities & 352 & 34.9 \\
\hline No problems & 189 & 65.8 \\
\hline Have problems & 356 \\
\hline Pain/discomfort & 185 & 32.4 \\
\hline No problems & \multicolumn{2}{|l}{} \\
\hline Have problems & 366 & 67.7 \\
\hline Anxiety/depression & 175 & \\
\hline No problems &
\end{tabular}

Abbreviations: CAD, coronary artery disease; HRQoL, health-related quality of life. having mild-to-moderate depression compared with younger subjects; adjusted OR was 5.76. Similarly, females had 1.56 times higher odds of having mild-to-moderate depression compare with males; when adjusted for other factors, the odds were 1.26 times higher. Higher socioeconomic status was also a risk factor for any depression (OR 1.76). Individuals with positive family history had 2.5 times higher odds compared with those who had negative family history and odds were similar (2.34) when adjusted for the factors (-Table $\mathbf{5}$ ).

\section{Discussion}

In our study, the prevalence of mild-to-moderate depression in the study population was around $30 \%$. This is high when compared with other studies where depression postmyocardial infarction (MI) ranged from $13 \%$ to $15 \%$ in USA. ${ }^{10}$ Another study showed that around $20 \%$ of cardiovascular patients were affected by depression. ${ }^{11}$ Severity of depression was more in another study done in India (35\% prevalence of major depressive disorder) among ischemic heart disease (IHD) patients. ${ }^{2}$

However, in our study, moderate depression was present in only three patients who warranted referral for counseling, while mild depression was observed in the majority. This could be due to the longer duration of disease duration in the study participants, which allows for various coping strategies as observed in the qualitative results. This may lead to better quality of life and hence levels of depression could be low. This was corroborated by the fact from an earlier study that depression reduced from $70 \%$ to $18 \%$ at the end of the year in the same study setting. ${ }^{12}$

However, it is possible that this may be high in the community which may not be able to access these services and hence are not under the radar of the health system. It should be noted that the study patients had access to hospital and are availing services. So, generalization of study results is not possible. Lower levels of moderate and severe depression in this study could indicate their coping capacity, quality of care they receive in the hospital, and the psychosocial support they receive from their home. Depression can occur in many

Table 3 HRQoL among patients with CAD attending cardiology clinic in a tertiary hospital, assessed by VAS $(N=541)$

\begin{tabular}{|l|l|l|l|}
\hline VAS & Rank & Frequency & Percentage \\
\hline Best imaginable & $100-70$ & 36 & 12.2 \\
\hline Moderate imaginable & $70-40$ & 439 & 81.1 \\
\hline Worst imaginable & below 40 & 66 & 6.7 \\
\hline
\end{tabular}

Abbreviations: CAD, coronary artery disease; HRQoL, health-related quality of life; VAS, visual analogue scale.

Table 4 Status of depressive symptoms among patients with CAD attending cardiology clinic in a tertiary hospital ( $\mathrm{N}=541)$

\begin{tabular}{|l|l|l|l|}
\hline Status of depression & Score & Frequency & Percentages \\
\hline None & $0-4$ & 379 & 70 \\
\hline Mild & $5-9$ & 159 & 29.4 \\
\hline Moderate & $10-14$ & 3 & 0.6 \\
\hline Moderate severe & $15-19$ & 0 & 0 \\
\hline Severe & $20-27$ & 0 & 0 \\
\hline
\end{tabular}

Abbreviation: CAD, coronary artery disease. 
Table 5 Association of sociodemographic and behavioral characteristics with presence of any depressive symptoms $(N=541)$

\begin{tabular}{|c|c|c|c|c|}
\hline Characteristics & $\begin{array}{l}\text { Total number } \\
(\boldsymbol{n})\end{array}$ & $\begin{array}{l}\text { Mild-to-moderate } \\
\text { depression } \boldsymbol{n}=162 \text { (30\%) }\end{array}$ & $\begin{array}{l}\text { Unadjusted OR } \\
(95 \% \mathrm{Cl})\end{array}$ & $\begin{array}{l}\text { Adjusted OR } \\
(95 \% \mathrm{Cl})\end{array}$ \\
\hline \multicolumn{5}{|l|}{$\mathrm{Age}^{\mathrm{a}}$} \\
\hline$<50$ years & 168 & $18(11.1)$ & 1 & \multirow{2}{*}{$\begin{array}{l}5.76^{a} \\
(2.86-8.47)\end{array}$} \\
\hline$\geq 50$ years & 373 & $144(88.9)$ & $\begin{array}{l}5.29 \\
(3.11-9.01)\end{array}$ & \\
\hline \multicolumn{5}{|l|}{ Gender $^{\mathrm{a}}$} \\
\hline Male & 397 & $128(79.1)$ & 1 & \multirow[t]{2}{*}{-} \\
\hline Female & 144 & 34 (20.9) & $\begin{array}{l}1.56 \\
(1.01-2.55)\end{array}$ & \\
\hline \multicolumn{5}{|l|}{ Educational status } \\
\hline Up to primary & 185 & $60(37.1)$ & $\begin{array}{l}1.20 \\
(0.81-1.76)\end{array}$ & \\
\hline Above 5th standard & 356 & 102 (62.9) & 1 & \\
\hline \multicolumn{5}{|l|}{ Occupation } \\
\hline Unemployed & 78 & $24(14.8)$ & $\begin{array}{l}1.05 \\
(0.6-1.76)\end{array}$ & \\
\hline Employed & 463 & $138(85.2)$ & 1 & \\
\hline \multicolumn{5}{|l|}{ Socioeconomic status ${ }^{a}$} \\
\hline Upper & 198 & $25(15.4)$ & $\begin{array}{l}1.90 \\
(1.17-3.08)\end{array}$ & \multirow[t]{2}{*}{$\begin{array}{l}1.76^{\mathrm{a}} \\
(1.05-2.95)\end{array}$} \\
\hline Lower & 343 & $137(84.6)$ & 1 & \\
\hline \multicolumn{5}{|l|}{ Family history ${ }^{a}$} \\
\hline Yes & 204 & $25(15.4)$ & $\begin{array}{l}2.50 \\
(1.72-3.65)\end{array}$ & \multirow[t]{2}{*}{$\begin{array}{l}2.34^{\mathrm{a}} \\
(1.57-3.47)\end{array}$} \\
\hline No & 337 & $137(84.6)$ & 1 & \\
\hline \multicolumn{5}{|l|}{ Smoking } \\
\hline Yes & 182 & $61(37.7)$ & $\begin{array}{l}1.29 \\
(0.88-1.89)\end{array}$ & \\
\hline No & 359 & $101(62.3)$ & 1 & \\
\hline \multicolumn{5}{|l|}{ Alcoholism } \\
\hline Yes & 91 & $28(17.2)$ & 1 & \\
\hline No & 450 & $134(82.8)$ & $\begin{array}{l}1.15 \\
(0.69-1.90)\end{array}$ & \\
\hline
\end{tabular}

Abbreviations: $\mathrm{Cl}$, confidence interval; OR, odds ratio.

${ }^{\text {a }} p$ value $<0.05$

chronic diseases, where patients are on prolonged treatments and their quality of life is affected. For example, depression in this study was lesser compared with 63\% depressive symptoms among epileptic patients in the same setting. ${ }^{13}$

CVD and depression are both highly prevalent disorders and reduces their quality of life and imposes economic burden on the patients. ${ }^{3}$ Early identification and timely management of depression among CAD patients is necessary to reflect positive health outcome and improve quality of life.

In this study, we found a higher risk of presence of any depression among older patients, and twice the risk when family history of CAD was reported. Female patients and upperclass women had mildly elevated risk for depression, and these were statistically significant. Different determinants have been reported in different studies and this can be explained by the sociocultural milieu of their community. Young patients, females, being diabetic and previous history of depression were found to be significant determinants of depression in a study.$^{10}$ In another Indian study, low literacy status, female gender, and the presence of type II diabetes mellitus were associated with psychiatric morbidity. ${ }^{2}$ Identification of people at high risk will help in screening of patients in an effective manner. This finding is comparable to earlier studies that have shown that among survivors of MI, depression and anxiety are key entry points and powerful predictors of quality of life. ${ }^{2}$

Overall, one-third of the participants reported some problems in their usual activities of self-care or mental health, and lesser people had problems in mobility. Poor quality of life was reported in another Indian study where majority (61.5\%) reported some difficulties; $24 \%$ patients reported inability to perform usual activities. Similar to our study, lesser proportion reported impairment in mobility in other settings. ${ }^{2}$ In a study conducted in Taiwan, the average EQ-5D index was 0.82 and mean VAS score was 77.8 ( \pm 13.6). One-third of the study participants reported problems in pain or discomfort and anxiety or depression 
similar to our study. Self-care domain was affected in least proportion of people (20\%). ${ }^{14}$ Similarly, in population-based studies on normal and high risk groups, impaired quality of life was reported in chronic diseases and patients with cardiovascular risk. ${ }^{15,16}$ Studies have shown that depression predicts subsequent quality of life, while others have shown that HRQoL is a risk factor for ongoing depression. ${ }^{17,18}$

The strength of our study is, the use of validated tools like PHQ9 and EQ5D3L, which enables comparison of these attributes across different settings and countries. Recall and social desirability bias could be a possible limitations in the study.

\section{Conclusion}

Assessment of HRQoL is becoming increasingly important in the management of CVD patients. Quality of the additional life years gained is as important as length of life. Moreover, poorer QOL predicts adverse health outcomes like mortality and hospitalization. It is important to ensure good HRQoL by providing emotional, social, and physical well-being. ${ }^{17,18}$ Social support influences the presence and severity of depression. This is the basis of planning psychosocial interventions in CVD patients. Treatment of depression may improve subsequent physical HRQoL; hence, it is vital to address both of them during their follow-up to improve their outcomes.

\section{Note}

The study had been approved from the JIPMER Ethics Committee on August 1, 2018.

\section{Authors' Contributions}

A.S. wrote the first draft of the manuscript with the support from L.S., D.K.G. and E.S. A.S. and E.S. performed data cleaning and preparation for analysis. D.K.G. and A.S. performed the analysis. L.S, S.S. and V.M. provided statistical support and critical review of the manuscript with subsequent revision. All the authors approved the final manuscript. The corresponding author L.S. attests that all listed authors meet authorship criteria and that no others meeting the criteria have been omitted. A.S. is the guarantor.

\section{Conflict of Interest}

None declared.

\section{Acknowledgment}

The authors would like to appreciate the support from all junior and senior residents in the Department of Cardiology who were helpful in the process of data acquisition.

\section{References}

1 Bunker SJ, Colquhoun DM, Esler MD, et al. "Stress" and coronary heart disease: psychosocial risk factors. Med J Aust 2003;178(6):272-276

2 John S. Prevalence and pattern of psychiatric morbidity and health related quality of life in patients with ischemic heart disease in a tertiary care hospital. Indian J Psychiatry 2013;55(4):353-359
3 Saran RK, Puri A, Agarwal M. Depression and the heart. Indian Heart J 2012;64(4):397-401

4 Lichtman JH, Bigger JT, Blumenthal JA, et al. Depression and Coronary Heart Disease Recommendations for Screening, Referral, and Treatment A Science Advisory From the American Heart Association Prevention Committee of the Council on Cardiovascular Nursing, Council on Clinical Cardiology, Council. Am Hear Assoc Journals. 2008;118(1):1768-1775

5 Smith SC Jr, Benjamin EJ, Bonow RO, et al. AHA/ACCF secondary prevention and risk reduction therapy for patients with coronary and other atherosclerotic vascular disease: 2011 update: a guideline from the American Heart Association and American College of Cardiology Foundation endorsed by the World Heart Federation and the Preventive Cardiovascular Nurses Association. J Am Coll Cardiol 2011;58(23):2432-2446

6 Roth GA, Johnson C, Abajobir A, et al. Global, regional, and national burden of cardiovascular diseases for 10 causes, 1990 to 2015. J Am Coll Cardiol 2017;70(1):1-25

7 Smarr KL, Keefer AL. Measures of depression and depressive symptoms: Beck Depression Inventory-II (BDI-II), Center for Epidemiologic Studies Depression Scale (CES-D), Geriatric Depression Scale (GDS), Hospital Anxiety and Depression Scale (HADS), and Patient Health Questionnaire-9 (PHQ-9). Arthritis Care Res (Hoboken) 2011;63(Suppl 11) :S454-S466

8 Tripathy S, Hansda U, Seth N, et al. Validation of the EuroQol five-dimensions - three-level quality of life instrument in a classical Indian language (Odia) and its use to assess quality of life and health status of cancer patients in eastern India. Indian J Palliat Care 2015;21(3):282-288

9 DiSante JL, Bires AM, Cline TW, Waterstram-Rich K. An Analysis of the Prevalence of depression post-myocardial infarction. Crit Care Nurs Q 2017;40(2):124-136

10 May HT, Horne BD, Knight S, et al. The association of depression at any time to the risk of death following coronary artery disease diagnosis. Eur Heart J Qual Care Clin Outcomes 2017;3(4):296-302

11 Ski CF, Jelinek M, Jackson AC, Murphy BM, Thompson DR. Psychosocial interventions for patients with coronary heart disease and depression: A systematic review and meta-analysis. Eur J Cardiovasc Nurs 2015;1(1):1-12

12 Menon V, Chandrasekaran R. Depressive and anxiety symptoms after myocardial infarction: a follow up study from south India. Malayasian J Psychiatry Online Early. 2012;1(1):1-11

13 Chandrasekharan SC, Menon V, Wadwekar V, Nair PP. High frequency of depressive symptoms among adults with epilepsy: Results from a Hospital-based study. J Neurosci Rural Pract 2017;8(5,Suppl 1):S13-S19

14 Tran BX, Moir MPI, Thai TP, et al. Socioeconomic inequalities in health-related quality of life among patients with cardiovascular diseases in Vietnam. BioMed Res Int 2018;2018(1):2643814

15 Ko HY, Lee JK, Shin JY, Jo E. Health-related quality of life and cardiovascular disease risk in Korean adults. Korean J Fam Med 2015;36(6):349-356

16 Tan Z, Liang Y, Liu S, et al. Health-related quality of life as measured with EQ-5D among populations with and without specific chronic conditions: a population-based survey in Shaanxi Province, China. PLoS One 2013;8(7):e65958

17 Dickens C, Cherrington A, McGowan L. Depression and health-related quality of life in people with coronary heart disease: a systematic review. Eur J Cardiovasc Nurs 2012;11(3):265-275

18 Sowden GL, Mastromauro CA, Seabrook RC, Celano CM, Rollman BL, Huffman JC. Baseline physical health-related quality of life and subsequent depression outcomes in cardiac patients. Psychiatry Res 2013;208(3):288-290 